\title{
Concentrations and Flux of Rare Earth Elements in a Semifield Plot as Influenced by Their Agricultural Application
}

\author{
Zijian Wang, ${ }^{*},{ }^{1}$ ChunXia Wang, ${ }^{1}$ Peng Lu, ${ }^{1}$ \\ AND WANGZHAO ZHU ${ }^{2}$ \\ 'State Key Laboratory of Environmental Aquatic Chemistry, \\ Research Center for Eco-Environmental Sciences, \\ Beijing 100085, People's Republic of China; \\ and, ${ }^{2} \mathrm{API}$, Delft University of Technology, Leeghwaterstraat 44, \\ 2628 CA Delft, the Netherlands
}

Received April 23, 2001; Accepted June 30, 2001

\begin{abstract}
The concentrations of rare earth elements (REs) in atmospheric particles, soil, soil water, surface runoff, and different parts of corn in an experimental plot in the suburb of Beijing, China were measured and the flux of REs was estimated. The concentration of REs in air particles with diameter less than $10 \mu \mathrm{m}$ is $36 \mathrm{ng} / \mathrm{m}^{3}$ and, by ratio analysis, the origin of REs in the atmosphere was likely local soil. The concentration of soluble REs is $0.69 \mu \mathrm{g} / \mathrm{L}$ in rainwater, $5-7 \mu \mathrm{g} / \mathrm{L}$ in surface runoff, as well as $1-4 \mu \mathrm{g} / \mathrm{L}$ in soil water and the application of RE mixture has no observed influences on their concentrations. The concentration of soluble REs in surface runoff and soil water was dominated by aqueous-solid-phase partitioning. By estimation of the flux, most of the REs applied will remain in the soil phase and continued application of REs will cause an accumulation of REs in agricultural soil.
\end{abstract}

Index Entries: Rare earth elements; concentrations; flux; agricultural soil.

\section{INTRODUCTION}

The application of rare earth elements (REs) in the world began in the middle of this century. In recent years, the scale of exploitation and appli-

*Author to whom all correspondence and reprint requests should be addressed. 
cation has rapidly increased. The world consumption of REs has been $30,000-50,000$ tons, $80 \%$ of which have been produced in China and $10 \%$ of which was used in the Netherlands. One important application of REs in China is in agriculture. Application of REs to soil or plants, by way of foliage dressing, could increase the crop production or improve the quality of plants (1). Since the 1980s, commercial mixtures of REs have been intensively applied in the agricultural activities of China. In addition, large amounts of REs enter the environment through the discharging of industrial or agricultural wastes, such as catalytic and magnetic materials and the utilization of phosphorus fertilizer (2).

Recently, more and more attention has been paid to the likely increase in environmental contamination from widespread industrial and agricultural use of REs and the adverse effects from long-term application of REs. Considerable effort has been devoted to the concentration distribution of REs in the soil and natural waters in different areas of China (3-6) and to the possible adverse effects of REs on soil and aquatic ecosystems $(7,8)$.

Whereas in past years, research papers on environmental behavior of REs have accumulated (9-14), the flux of REs in the soil ecosystem and the influence of agricultural application of REs on the flux were still lacking. In this article, the time-dependent concentrations of REs in atmospheric particles, rain, runoff, soil, and different parts of corn in a semifield plot in the suburb of Beijing were measured and the influence of application of REs on the concentrations and flux of REs were evaluated. The REs contamination in groundwater and cereal food as well as long-term accumulation in soil are discussed.

\section{MATERIAL AND METHODS}

\section{Experiment Design and Sampling}

The experiment was carried out in a suburb of Beijing. The soil type was Luvisols (FAO soil classification) and mainly consisted of light REs. Concentrations of REs in the soil profile were relatively constant (data not shown), indicating an insignificant input of REs after soil formation. The basic properties of the soil are shown in Table 1. The composition and concentrations of RE in topsoil are shown in Table 2. The soil contains sufficient nitrogen and phosphorus (Table 1) for plant growth. Because phosphate may affect the mobility of REs by forming insoluble RE-phosphate salt, additional fertilizer was not applied during the experiment.

The semifield plot experiment was designed to contain four plots each with an area of $12 \mathrm{~m}^{2}$. Three plots were set for the different treatments, and the other was set as the control. Two ditches were constructed, which lead to two small cells, used for collecting runoff from the treatments and the control. All plots were planted with spring corn (Zea mays sp. Zhongxia-9). 


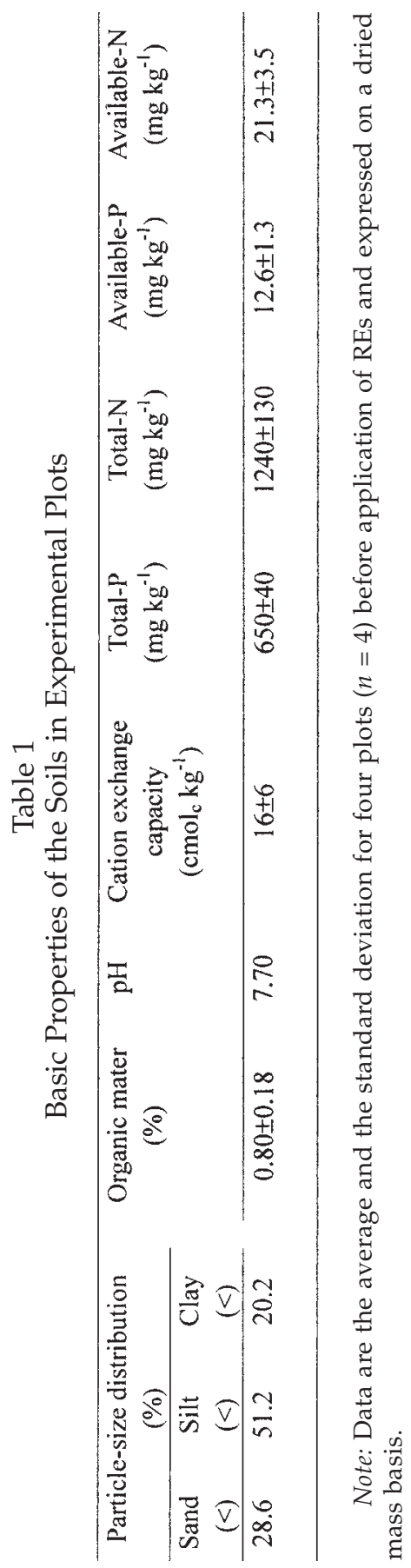


Table 2

Concentrations of RE in Solution Prepared for Foliage Dressing and in Plot Soil

\begin{tabular}{|c|c|c|c|c|}
\hline \multirow[t]{2}{*}{$\mathrm{RE}$} & \multicolumn{2}{|c|}{ In solution for application of REs } & \multicolumn{2}{|c|}{ In plot soil } \\
\hline & Concentration $\left(\mu \mathrm{g} l^{-1}\right)^{1}$ & $\mathrm{La} / \mathrm{RE}$ & Concentration $\left(\mathrm{mg} \mathrm{kg}^{-1}\right)$ & $\mathrm{La} / \mathrm{RE}$ \\
\hline $\mathrm{La}$ & 39746 & & 31.2 & \\
\hline $\mathrm{Ce}$ & 18975 & 2.09 & 69.1 & 0.45 \\
\hline $\operatorname{Pr}$ & 7918 & 5.02 & 7.9 & 3.95 \\
\hline $\mathrm{Nd}$ & 12004 & 3.31 & 28.5 & 1.10 \\
\hline $\mathrm{Sm}$ & 1206 & 33.0 & 5.3 & 5.89 \\
\hline $\mathrm{Gd}$ & 738 & 53.9 & 4.6 & 6.78 \\
\hline Dy & 16 & 2484.1 & 3.5 & 8.91 \\
\hline Total & 80603 & & 150.2 & \\
\hline
\end{tabular}

${ }^{1}$ When applied, the stock solution was diluted and adjusted to the same volumes for different treatments.

A commercial mixture of REs, known as Changle, was obtained from the China Center for Agricultural Application of REs. The mixture contained negligible amounts of nitrogen and phosphorus as impurities and was applied by means of foliage dressing. The composition of the REs mixture and the concentration of REs in the applied solutions are given in Table 2. Among treatments, the REs mixture was applied in dosages of 16, 32 , and $64 \mathrm{mg} / \mathrm{m}^{2}$, respectively, by adjusting the volumes of the application. These dosages correspond to onefold, twofold, and fourfold, respectively, practical utilization of REs by Chinese farmers. One plot was set as the control, where only water was applied. Application of REs causes no significant increase in RE concentrations in topsoil, because it is negligible in comparison to the total REs in topsoil.

Air sampling was executed using an atmospheric total suspended particle (TSP) collector. The TSP collector was set at $1.5 \mathrm{~m}$ above the ground. Air was sampled $10 \mathrm{~d}$ before and $3 \mathrm{~d}$ after the application of REs with a $10.0-\mu \mathrm{m}$ membrane at a flow rate of $20-28 \mathrm{~L} / \mathrm{min}$ for 347-460 min. The total sampling volume was recorded for calibrating the data, and the final data were expressed as a volume concentration $\left(\mu \mathrm{g} / \mathrm{m}^{3}\right)$. The filter was digested directly; therefore, only volume concentrations of REs in the atmosphere could be reported.

Rainwater was collected by a rainfall tank placed near the plot, and the rain volume was recorded after each rainfall. The surface runoff was sampled after each rainfall event from the cells connected to the ditches, and the runoff volumes were recorded. The suspended matter in the storm runoff was collected through the filtration of water in cells through a $0.45-\mu \mathrm{m}$ Millipore membrane.

Three soil samples (top $20 \mathrm{~cm}$ ) were collected from different parts of each plot at the day of harvest. In each plot, three soil-water samplers were placed at depth of 15, 45, and $90 \mathrm{~cm}$, respectively, in a soil profile for col- 
lecting soil waters. The soil-water sampler used in the study consists of a porous porcelain head $(\varnothing 2 \times 6 \mathrm{~cm})$ and a hollow pipe, which is connected to a three-way flask through a Latex tube. The flask was kept under pressure by a hand-operated vacuum pump, and soil water infiltrated into the porous porcelain head could be collected above ground under vacuum conditions. After collection, soil water was filtered through a $0.45-\mu \mathrm{m}$ Millipore membrane and acidified immediately after filtration using one drop of concentrated nitric acid.

From each plot, five whole plants were sampled from different parts of each plot at the day of harvest of plants or $57 \mathrm{~d}$ after the application of REs. The plant was washed with tap water thoroughly to remove soil and then with distilled water three times. Different parts of the plant were separated (root, stem, leaf, flower, and grain) and were weighed. To calculate the flux of REs through plantation, the total number of plants in each plot was counted and the biomasses were calculated.

\section{Sample Preparation and Chemical Analysis}

Soil samples were dried at room temperature, gently ground, and passed through a 80-mesh sieve. Shortly after pretreatment, 0.1 -g soil sample was put in a 50-mL Teflon vessel and wetted by several drops of quartz-distilled water. One milliliter of $\mathrm{HNO}_{3}, 1 \mathrm{~mL}$ of $\mathrm{HClO}_{4}$, and $5 \mathrm{~mL}$ of $\mathrm{HF}$ were added in this sequence. The capped mixture was heated at $100^{\circ} \mathrm{C}$ for $4 \mathrm{~h}$ and then heated without a cap until no smoke appeared. One milliliter of $\mathrm{HNO}_{3}, 1 \mathrm{~mL}$ of $\mathrm{HClO}_{4}$, and $1 \mathrm{~mL}$ of quartz-distilled water were added, and it was heated until a transparent solution was obtained. The resulting solution was added with an ${ }^{115}$ In internal standard and diluted to $50 \mathrm{~mL}$ using quartz-distilled water.

Subplant samples were dried in a microwave oven and ground to pass through a 1-mm sieve. Each $0.5-\mathrm{g}$ subplant sample was treated with $8 \mathrm{~mL}$ of a mixed oxidizing solution $\left(15 \mathrm{~mol} / \mathrm{L} \mathrm{HNO}_{3}: 9 \mathrm{~mol} / \mathrm{L} \mathrm{H}_{2} \mathrm{O}_{2}\right.$ or $5: 3$ $[\mathrm{v} / \mathrm{v}]$ ) and digested for $30 \mathrm{~min}$ at $80 \mathrm{psi}$ in a microwave oven (CEM Corporation, Matthews, Missouri, USA). The solution was diluted to a final volume of $25 \mathrm{ml}$ with deionized water before analysis.

Surface runoff was filtered to separate the suspended matter from the solution before analysis. The separated suspended matter was dried at room temperature and digested by the same procedure as the soil sample. The sample of air particles was digested in a similar manner to the soil or suspended matter.

The concentration of REs was determined with a Plasma Quard II ICP-MS spectrometer (Fisions Instruments Elemental Analysis, Cheshire, UK). The instrument was run at sampling rate of $1.0 \mathrm{ml} / \mathrm{min}$ with a measuring time of $40 \mathrm{~s}$. Indium $\left({ }^{115} \mathrm{In}\right)$ was used as an internal standard for calibrating the instrument and barium chloride was used as an external standard for calibrating the concentration. The stock solution of each RE $(1000 \mu \mathrm{g} / \mathrm{mL})$ was obtained from the National Research Center for Certi- 
fied Reference Materials, Beijing, China, which was used to obtain the calibration curves after dilution.

\section{Statistical Analysis and Data Quality}

The heterogeneity of soil in the semifield plots could be shown by the measured basic properties of soil (mean and standard deviation for four plots before application of REs, Table 1) and the deviations were mostly less than $15 \%(n=4)$. Concentrations of REs in soil and subplant samples were transformed to a dried-weight basis. The mean and standard deviation for three replicates of soil and five subplant samples in each plot were calculated by using the statistical function in Excel (version 2000). Analysis for the concentration of REs in rainwater, air particles, runoff water, and soil water were all single run for each sampling date. The accuracy of RE analysis was checked by the determination of REs in the certified reference materials (GSS-1 of soil and GBW 07605 of tea from the National Research Center for Certified Reference Materials, Beijing, China) and the results deviated by less than $10 \%$ from the accepted values (9). The precision of the instrument determination of REs was evaluated by analyzing duplicated samples (subplant, soil, water, etc.) and it was found that the relative standard deviation (RSD) was below $20 \%$ for the various individual REs.

\section{RESULTS AND DISCUSSIONS}

\section{Concentrations of REs in the Surrounding Air}

In the area surrounding the plots, the concentration of REs in air particles with a diameter less than $10 \mu \mathrm{m}$ increased from $35.7 \mathrm{ng} / \mathrm{m}^{3}$ before application to $93.5 \mathrm{ng} / \mathrm{m}^{3}$ after the application of REs. As can be seen from Fig. 1, the concentrations of REs in particles from air surrounding the plot obviously increased after its application and the concentration distribution of different REs followed the odd-even rule of the elements in earth crust. The majority of REs was occupied by light ones, such as $\mathrm{La}, \mathrm{Ce}, \mathrm{Pr}$, and Nd, whose concentrations exceeded $95 \%$ of the total REs in the air-particle samples. Similar results were reported by Olmez and Gorden (10). Before application, the ratio of $\mathrm{La} / \mathrm{Ce}$ in air particles was 0.55 , which was close to that in the plot soil (0.45) and in other types of soils in China (12), but it deviates significantly from the RE mixture (2.09). The La/Ce ratio analysis may indicate that the airborne REs may originate from local ground dust. After the application of REs, the ratio of La/Ce in air particles increased to 0.66. The increase in REs concentration and $\mathrm{La} / \mathrm{Ce}$ ratio in air particles indicates that the sprayed REs or respiratory REs from plants were bound to air-bound particles before being slowly precipitated or washed to the ground. Our previous results showed that the concentration of REs in air particles depends on particles size and the finer particle corresponds to lower concentrations of REs (13). 


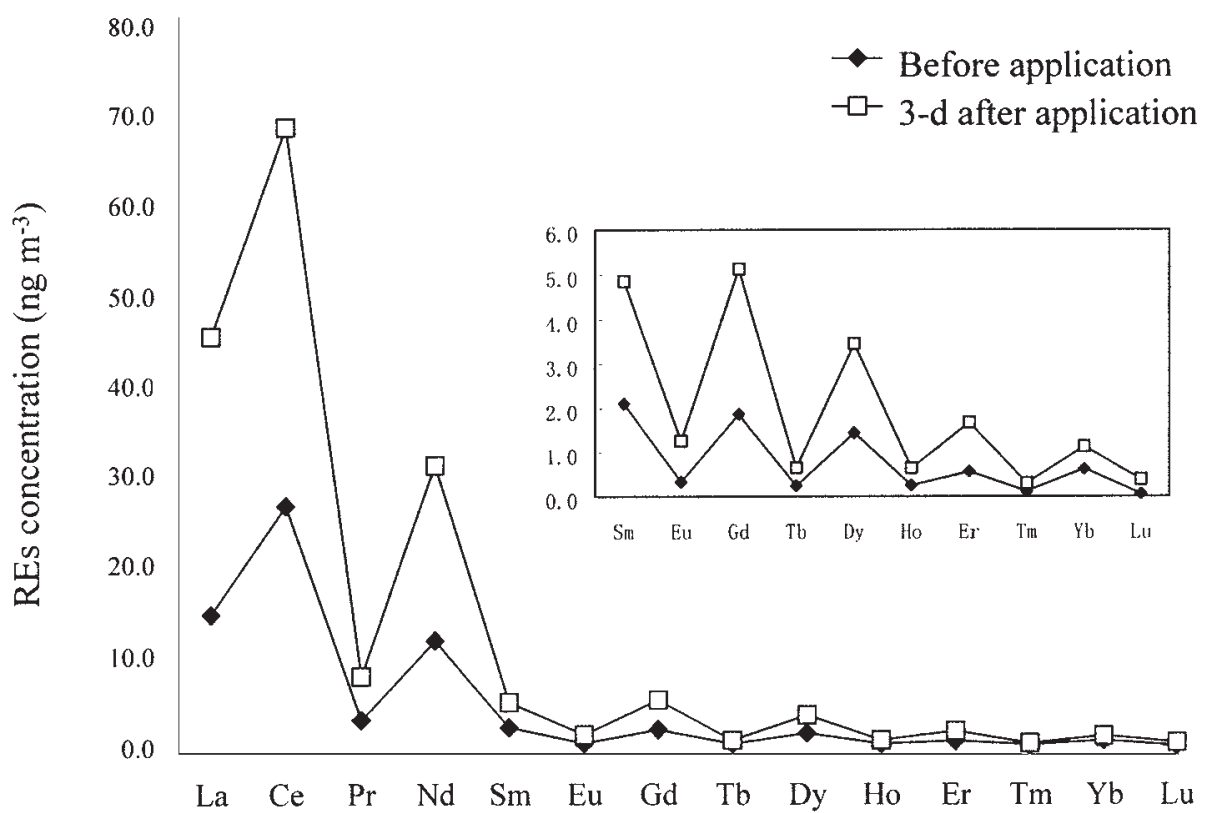

Fig. 1. The concentrations of REs in particles from air surrounding the experimental plots before and after the application of REs.

\section{Concentrations of REs in Rainwater}

Twelve rainfall samples have been collected in $50 \mathrm{~d}$ during the experiment. Among 12 rainwater samples, the maximum concentration of REs occurred at the first rainfall $(2.42 \mu \mathrm{g} / \mathrm{L})$. In the following rainfall events, the concentration of REs in rainwater decreased gradually to a stable level and fluctuated at the mean value of $0.69 \pm 0.21 \mu \mathrm{g} / \mathrm{L}$ (Fig. 2). The results indicated that there was a washing process, in which REs bound to the air sol $(<0.45 \mu \mathrm{m})$ were gradually precipitated to the ground. We take the mean value $\left(0.69 \mu \mathrm{g} \mathrm{l}^{-1}\right)$ as the concentration of REs in the clean rainwater in summer in Beijing. The REs in rainwater mainly consisted of $\mathrm{La}, \mathrm{Ce}, \mathrm{Nd}$, and $\mathrm{Sm}$ and the ratio of $\mathrm{La} / \mathrm{Ce}$ was 0.55 , similar to that in air particles. The concentrations of heavy REs were less than $0.001 \mu \mathrm{g} / \mathrm{L}$ in rainwater.

The averaged rainfall in Beijing is $500 \mathrm{~mm}$ and we collected $257 \mathrm{~mm}$ during the experiment, which was about half of the annual rainfall. The annual input of REs to the experiment plot through rainfall was estimated to be $4 \mathrm{~g} / \mathrm{ha}$. This input was negligible, in comparison with the input from annual agricultural application of REs (160 g/ha).

\section{Concentrations of REs in Runoff}

Surface runoff occurred only during a storm. Ten storm runoff samples were collected from control or treatment plots during the experiment. Soluble REs in runoff mainly consisted of light REs and their concentra- 


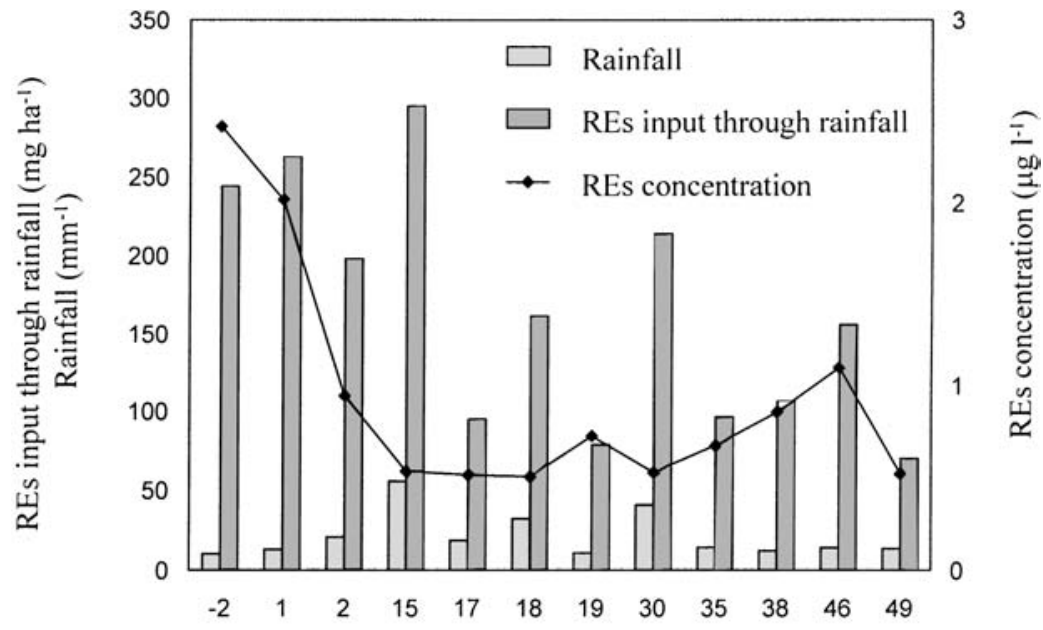

Sampling time (days after application)

Fig. 2. The concentration of REs in the rainwater of a suburb of Beijing in the summer.

tions fluctuated considerably (Table 3). In general, concentrations of soluble REs in runoff were in the range 1.50-15.05 $\mu \mathrm{g} / \mathrm{L}$ and were higher than those in rainwater $(0.50-2.42 \mu \mathrm{g} / \mathrm{L})$. By statistic analysis for the runoff samples between the control and treatment plots (one-way analysis of variance [ANOVA], $p>0.01, n=10$ ), concentrations of soluble REs were independent of the REs application. Based on the observation that a lower concentration of soluble REs corresponded to higher rainfall amount (data not shown), the concentration of soluble REs in runoff was governed by the partitioning of REs between water and solid phases.

Because the concentration of soluble REs in runoff was higher than that in rainwater, runoff caused a net loss of REs from soil after each rainfall. The total runoff volumes collected during the experiment were 0.57 and $0.59 \mathrm{~m}^{3}$ in experimental and control plots, respectively. The calculated output of soluble REs from runoff corresponded to 0.7 and $1.4 \mathrm{~g} / \mathrm{ha}$ in experimental and control plots, respectively. Assuming only half the runoff in the year was collected, annual net loss of REs through runoff corresponded to 1.4 and $2.8 \mathrm{~g} / \mathrm{ha}$.

The applied concentration of REs as the REs mixture was as high as $80 \mathrm{mg} / \mathrm{L}$ in a chemical form of nitrate (Table 2). In comparison, the concentration of REs in runoff was much lower. This result demonstrated that the applied REs transformed quickly into insoluble forms or was strongly adsorbed on soil particles. Similar conclusions were drawn in previous works $(10,14,15)$.

The mean concentrations of REs in the suspended matter in five collected runoff samples were $174.3 \mathrm{mg} / \mathrm{kg}$ in control and $146.5 \mathrm{mg} / \mathrm{kg}$ in 
Table 3

Concentrations of Soluble REs in Runoff Samples $(n=10)$

\begin{tabular}{ccccccc}
\hline & \multicolumn{3}{c}{ Concentration $\left(\mu \mathrm{g} \mathrm{l}^{-1}\right)$} & \multicolumn{3}{c}{ Concentration $\left(\mu \mathrm{g} \mathrm{^{-1 } )}\right.$} \\
\hline & Lowtrol Plot & & \multicolumn{3}{c}{ Experimental Plot } \\
\hline $\mathrm{La}$ & 0.34 & Highest & Mean & Lowest & Highest & Mean \\
$\mathrm{Ce}$ & 0.99 & 5.15 & 1.35 & 0.28 & 3.34 & 1.22 \\
$\mathrm{Nd}$ & 0.32 & 2.34 & 3.09 & 0.49 & 3.63 & 1.87 \\
$\mathrm{Sm}$ & 0.00 & 0.89 & 0.43 & 0.21 & 1.45 & 0.62 \\
$\mathrm{Pr}$ & 0.14 & 0.61 & 0.36 & nd & 5.23 & 0.65 \\
$\mathrm{Gd}$ & nd & 0.96 & 0.31 & nd & 0.59 & 0.20 \\
$\mathrm{Dy}$ & 0.06 & 0.77 & 0.27 & nd & 2.38 & 0.37 \\
Total & 2.04 & 11.53 & 7.07 & 1.50 & 0.30 & 0.14 \\
\hline
\end{tabular}

Note: nd $=$ not detectable.

treatments (Table 4), which were not significantly deviated from that in the plot soil (Table 2). There were no significant difference regarding both individual and total REs concentrations between the control and treatment (one-way ANOVA, $p>0.01, n=5$ ). The La/Ce ratios for REs in suspended matter were similar to each other and close to that in the plot soil, rather than to that in REs mixture. Therefore, the output of REs in the form of suspended matter could be regarded as the results of soil erosion and was not influenced by the application of REs. The intensity of soil erosion was positively correlated with local rainfall intensity (16) and, therefore, the output of REs through suspended matter in runoff is a function of rainfall intensity. Calculating from the total mass of suspended matters in experimental ditches, REs carried by suspended matters in runoff was $200 \mathrm{~g} / \mathrm{ha} / \mathrm{yr}$.

\section{REs Concentration in Soil Water}

The concentration of REs in soil water ranged within 1-4 $\mathrm{gg} / \mathrm{L}$ (Fig. 3). The mean concentration of soluble REs in soil water was lower than that in runoff but higher than that in rainwater. The concentrations at a depth of $90 \mathrm{~cm}$ were slightly lower than the concentrations at depths of 15 and $45 \mathrm{~cm}$, especially $20 \mathrm{~d}$ after the application of the RE mixture. High concentrations of REs were observed at depths of 15 and $45 \mathrm{~cm}$ for treatment of higher dosages (32 and $64 \mathrm{mg} / \mathrm{m}^{2}$ ), compared with control. At a depth of $90 \mathrm{~cm}$, the concentrations of REs in soil water were almost constant between control and treatment plots. Similar to the observation for concentrations of soluble REs in runoff water, the application of REs to soil had an insignificant influence on the concentrations of REs in soil water, because of quick immobilization of applied soluble RE-nitrates in the soil phase. From the results, one could conclude that the downward movement of applied REs through water movement in the soil column and the potential infiltration of applied REs into ground water were negligible. 


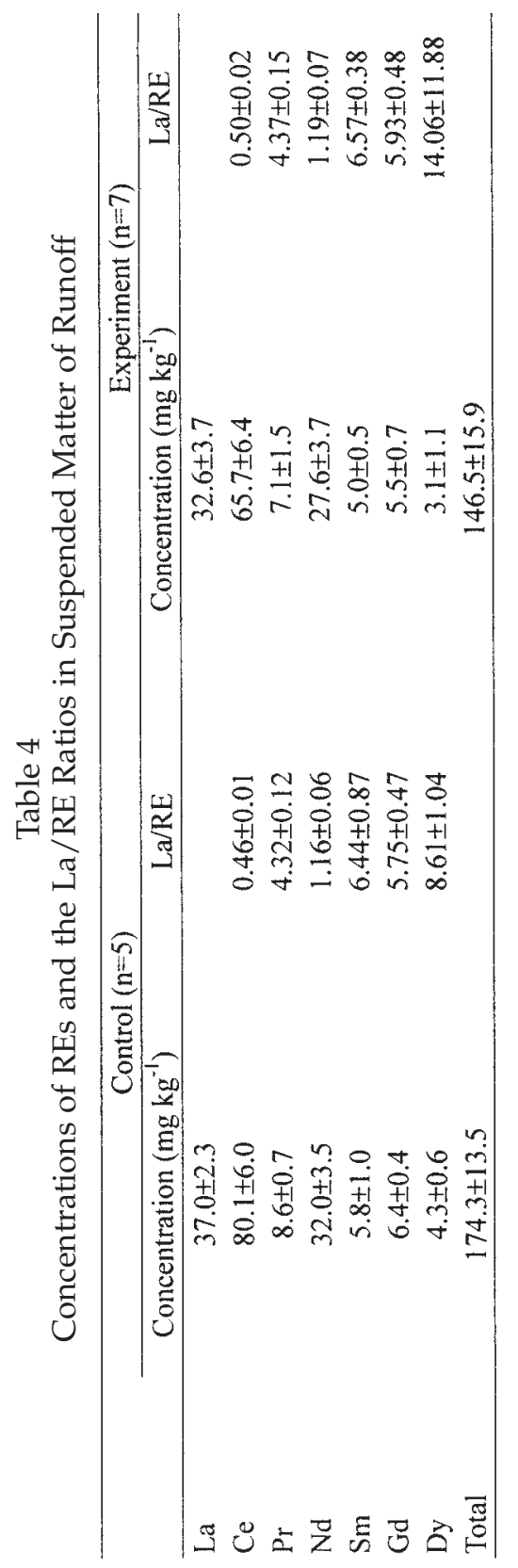




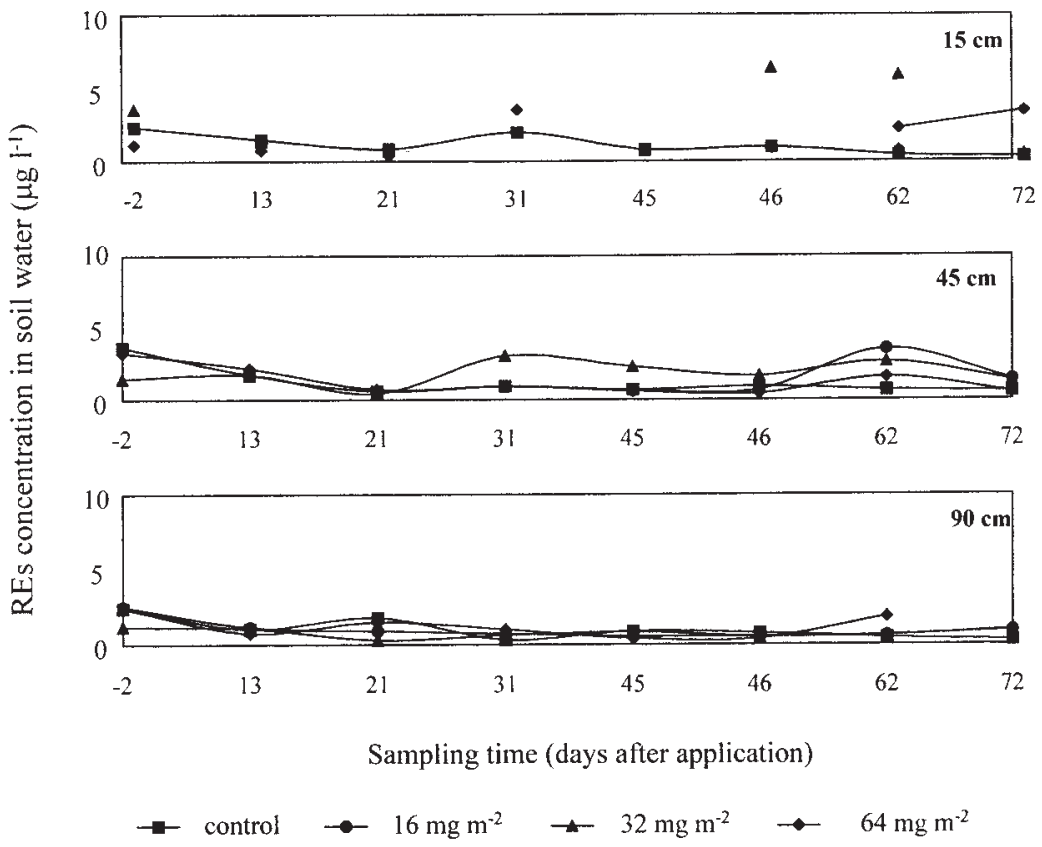

Fig. 3. Variation of REs concentration in soil water at three different depths in the soil profile as a function of sampling date and application of RE mixture.

\section{REs Concentration in Subplant Samples}

The dose-dependent accumulation of REs in a plant of different growth periods has been reported elsewhere (17). At the day of harvest, REs concentrations in plant root, leaf, and stem increased in comparison with those in the control plot. REs concentrations in different parts of plants followed the decreasing order root $>$ leaf $>$ flower $>$ stem $>$ grain. The application of REs did not change the order. Similar observations have been reported by other authors (5), except that some authors reported the decreasing order leaf $>$ root in cases where REs were applied in the manner of foliage dressing (18). Table 5 shows the concentrations of REs, biomass, and REs carried out by biomass at the day of harvest. As it shows, the plant root carried major part of REs, whereas its biomass was less than $10 \%$ of the total biomass. Because Chinese farmers do not remove plant roots from land, harvested aboveground parts of plants should remove 16-55 g REs per hectare. Among different aboveground parts of plants, the plant leaf removed the greatest amount of REs, which is generally used for animal feed. The plant seed carried the smallest amount of REs, which is partially used for human consumption. In addition, the applied REs were 160-640 g/ha and harvest removed only 6-10\%. Most parts of the applied REs should remain in the soil and the long-term accumulation in continuous application of REs is therefore an important consideration. 


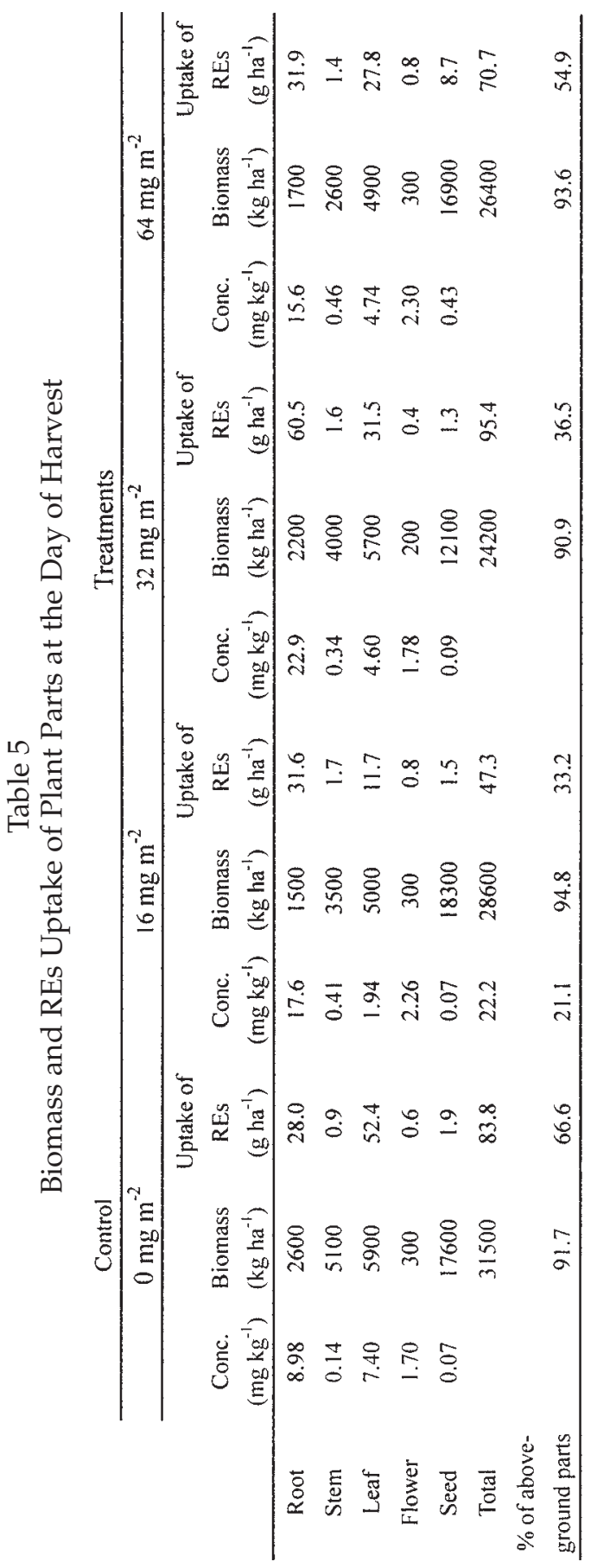




\section{REs Flux in Soil Plots}

The flux of REs in soil plots could be estimated based on their concentration distributions in different compartments and the mass transfer among compartments. The input of REs through the application of the RE mixture resulted in a total of 160-640 g/ha. The rainfall input contributed $4 \mathrm{~g} / \mathrm{ha}$. Our calculation did not account for REs carried by air particles (dry deposition) and by suspended matters in runoff (soil erosion). Another important inputting source of REs in agriculture is through the application of fertilizer, which contributes about $5 \mathrm{~g} /$ ha (data not shown). This input can be neglected in this study because fertilizer was not applied during our experiment.

The output of soluble REs through runoff is about 1.4-2.8 g/ha. The output of REs to groundwater should be negligible, because the total volume of water percolation through a $90-\mathrm{cm}$ soil profile could be negligible. The output through crop harvest could be calculated for aboveground parts of plant and is $16-55 \mathrm{~g} / \mathrm{ha}$, corresponding to $6-10 \%$ of the applied REs.

\section{CONCLUSIONS}

The background levels of REs in suburb of Beijing are as follows: The concentration of REs in air particles with a diameter less than $10 \mu \mathrm{m}$ is $36 \mathrm{ng} / \mathrm{m}^{3}$ and, by ratio analysis, the origin of REs in the atmosphere was likely local soil. The concentration of soluble REs is $0.69 \mu \mathrm{g} / \mathrm{L}$ in rainwater, $5-7 \mu \mathrm{g} / \mathrm{L}$ in surface runoff, and $1-4 \mu \mathrm{g} / \mathrm{L}$ in soil water. The concentration of soluble REs in surface runoff and soil water was controlled by the aqueous-solid-phase partitioning and there is a quick immobilization of applied soluble RE-nitrates. Most of the REs applied will remain in the soil phase and cause an accumulation of REs in agricultural soil.

\section{ACKNOWLEDGMENTS}

This work was supported by the National Natural Science Foundation of China (29890280-2-3) and the project of RCEES-KIP-9901. The international collaboration was supported by Koninklijke Nederlandse Akademie van Wetenschappen. The authors were grateful to Mr. Pierre del Castilho from AB-DLO (Wageningen, The Netherlands) for his meaningful discussions and careful revision of the manuscript. Part of the analytical work was done in the TNO Institute of Environmental Sciences, Energy Research and Process Innovation and we are grateful for their technical assistance.

\section{REFERENCES}

1. X. X. Gao, Agricultural Application and Electroanalytical Chemistry of the Rare Earth Elements, Peking University Publisher, Beijing (1997) (in Chinese). 
2. A. A. Volokh, A. V. Gorbunov, S. F. Gundorina, B. A. Revich, M. V. Frontasyeva, and S. P. Chen, Phosphorus fertilizer production as a source of rare-earth elements pollution of the environment. Sci. Total Environ. 95, 141-148 (1990).

3. A. Peng and Z. Wang, Recent research progress on environmental chemistry of rare earth element, Huanjing Kexue Jinzhan 3, 22-32 (1995) (in Chinese).

4. S. Zhang, L. J. Wang, and C. S. Zhang, Neutron activation technique and geo-biochemical behavior of rare-earth elements, in Modern Nuclear Analysis and its Application in Environment, S. Zhang, ed. Publisher for Nuclear Energy, Beijing, pp. 199-210 (1994) (in Chinese).

5. J. Z. Ni, Bioinorganic Chemistry of Rare Earth Elements, Chinese Science Publisher, Beijing (1995) (in Chinese).

6. W. X. Ding, Rare earth elements in Chinese soils, J. Chin. Rare Earth Soc. 15, 44-48 (1995) (in Chinese).

7. H. Ichihashi, M. Hideyoshi, and T. Ryo, Rare earth elements (REs) in naturally grown plants in relation to their variation in soils, Environ. Pollut. 76, 157-162 (1992).

8. M. Boger, Y. H. M. Van Erp, and P. Eichner, Assessment of the potential toxicity of lanthanum for aquatic organism, in Proceedings of the 2nd Sino-Dutch Workshop on the Environmental Behavior and Ecotoxicology of Rare Earth Elements and Heavy Metals, R. Guieherit and W. Zhu, eds., TNO, Delft, The Netherlands, pp. 14-18 (1997).

9. S. Zhang and X. Q. Shan, Determination of rare earth elements in soil by inductively coupled plasma mass spectrometry. Atomic Spectrosc. 18, 140-144 (1997).

10. I. Olmez and G. E. Gordon, Rare earth: atmospheric signatures for oil-fired power plants and refineries, Science 229, 966-969 (1985).

11. P. H. Brown, A. H. Rathjen, R. D. Graham, and D. E. Tribe, Rare earth elements in biological systems, in Handbook on the Physics and Chemistry of Rare Earth, Volume 13, K. A. Gschneidner, Jr. and I. Eyring, eds., Elsevier Science, Amsterdam, pp. 423-452 (1990).

12. R. Ran and Z. Liu, Content and distribution of rare earth elements in soil of China, J. Chin. Rare Earth Soc. 12, 248-252 (1994) (in Chinese).

13. C. X. Wang, W. Z. Zhu, Z. Wang, and R. Guicherit, Rare earth elements and metals in the atmospheric particulate matters in the western part of the Netherlands, Water Air Soil Pollut. 121(1/4), 111-120 (2000).

14. Z. X. Chen, X. R. Wang, and L. Q. Tian, Study on the speciation and availability of exogenous rare earth in soil, J. Chin. Rare Earth Soc., 13(1), 74-77 (1995) (in Chinese).

15. Y. L. Liu, J. H. Liu, Z. Wang, and A. Peng. Speciation transformation of added rare earth elements in soil, Huanjing Huaxue 18, 393-397 (1999) (in Chinese).

16. Q. Cai, S. J. Ma, S. Wu, and X. T. Hong, The intensity of erosion and storm runoff from different types of soils in Huabai plain, in Water Pollution Control in Baiyangdian Area, China, S. Zhang and Y. A. Tang, eds., China Science Publisher, Beijing, pp. 75-81 (1995).

17. Z. Wang, D. F. Liu, P. Lu, and C. X. Wang, Accumulation of rare earth elements in corn after agricultural application, J. Environ. Qual. 30, 37-45 (2001).

18. J. X. Sun and H. Zhao, Concentration and distribution of rare earth elements in wheat and rice, Kexue Tongbao 37(24), 2273-2280 (1992) (in Chinese). 